\title{
Knowledge on the Pathogenesis and New Diagnosing Techniques Approach for Low SARS-CoV-2 Testing Rates: A Case Study of Nigeria
}

\author{
Abass Abdulateef Ohilebo ${ }^{1,2 *}$, Samuel Olarewaju Ogunsola ${ }^{3}$, Abdullahi Tunde Aborode ${ }^{4}$, \\ Ademola Emmanuel Aiyenuro ${ }^{5}$
}

${ }^{1}$ Department of Biochemistry, Ambrose Alli University Ekpoma, Edo State, NIGERIA
${ }^{2}$ Centre for BioCode, NIGERIA
${ }^{3}$ Department of Biochemistry, Federal University of Technology, Akure, Ondo State, NIGERIA
${ }^{4}$ Shaping Women in STEM (SWIS) Africa Research Hub, NIGERIA
${ }^{5}$ Department of Microbiology, Federal University of Technology, Akure, Ondo State, NIGERIA
${ }^{*}$ Corresponding Author: abassohilebo@gmail.com

Citation: Ohilebo, A. A., Ogunsola, S. O., Aborode, A. T. and Aiyenuro, A. E. (2021). Knowledge on the Pathogenesis and New Diagnosing Techniques Approach for Low SARS-CoV-2 Testing Rates: A Case Study of Nigeria. European Journal of Environment and Public Health, 5(1), em0064. https://doi.org/10.29333/ejeph/9145

ARTICLE INFO

Received: 17 Jun. 2020

Accepted: 5 Sep. 2020

\begin{abstract}
SARS-CoV-2 (novel coronavirus responsible for coronavirus disease 2019) is a beta $(\beta-)$ sub-class of the coronavirus which has caused more harm to live than expected. SARS-CoV-2 which was declared as a pandemic by the World Health Organization (WHO) on 11 March 2020, has caused governments globally to declare and implement the "lock down" policy for its citizen, including Nigeria with a large population in Africa. The country National Centre for Disease Control (NCDC) made it known the testing methods adopted by them are not effective at curtaining the large population of her citizens. Our main goal in this review is to focus on the SARS-CoV-2 pathogenesis and new diagnostic techniques approaches that can be adopted in Nigeria. A total of 88,432 testing has been carried out by the NCDC, with 14,554 confirmed cases in 200 million populations. Although the SARSCoV-2 test adopted by the NCDC has been on the molecular testing using real-time reverse transcriptase polymerase chain reaction (RT-PCR) and antibody tests using blood, which has many demerits. We therefore recommend the NCDC should approach new diagnostic techniques like use of saliva samples and loop-mediated isothermal amplification (LAMP). Conclusively, when these methods are considered, testing rates will greatly improve.
\end{abstract}

Keywords: SARS-CoV-2, diagnostic methods, World Health Organization, Nigeria

\section{INTRODUCTION}

The coronavirus ( $\mathrm{CoV})$, which belongs to the family "Coronaviridae" is organised into four sub-families: alpha $[\alpha-]$, beta $[\beta-]$, delta $[\delta-]$ and gamma $[\gamma-]$ CoV. However, only $\alpha$ - and $\beta$-CoVs are known to cause disease in humans (deWilde et al., 2011; Weiss and Leibowitz, 2011). Primary types of CoV, Middle East respiratory syndrome-coronavirus (MERS-CoV) and Severe Acute Respiratory Syndrome-Coronavirus (SARSCoV-1) both have $30.1 \mathrm{~kb}$ and $27.9 \mathrm{~kb}$ size single-stranded RNA respectively (Monchatre-Leroy et al., 2017). The other known human coronaviruses (HCoV) that cause human infections are $\mathrm{HCoV}-229 \mathrm{E}$, and HCoV-NL63 ( $\alpha-\mathrm{CoVs}) ; \mathrm{HCoV}-\mathrm{OC} 43$, and HCoV-HKU1 ( $\beta$-CoVs) having mild respiratory symptoms like colds, with minimal pathogenesis (Cui et al., 2019).
Respiratory syndrome coronavirus (SARS-CoV-2) causes COVID-19, which leads to severe acute respiratory syndrome. This novel coronavirus is about $29.9 \mathrm{~kb}$ in size and was first reported in Wuhan, China on December 31, 2019 (Wu et al., 2020). From its phylogenetic interactions and genomic structures, SARS-CoV-2 belongs to genera $\beta$-coronavirus by the World Health Organization (WHO) (Guo et al., 2020). Chinese scientists quickly distinguished SARS-CoV-2 from a patient within a short period on 7 January 2020 and came out with genome sequencing ( $\mathrm{Lu}$ et al., 2020). SARS-CoV-2 has caused significant deaths globally, with Nigeria not an exception, prompting WHO to declare the outbreak a pandemic and government to implement the "lock down" legislation and other preventive measures (Ajari, 2020) and standard of care should remain the base of SARS-CoV-2 therapy (Oluwafolajimi et al., 2020). 
Nigeria first reported SARS-CoV-2 case was confirmed on February 27, 2020. The case was confirmed as an Italian citizen who returned from Milan to Nigeria on the 25th of February 2020, by the Virology Laboratory of the Lagos University Teaching Hospital (LUTH), part of the Laboratory Network of the Nigeria Centre for Disease Control. At African Centre of Excellence for the Genomics of Infectious Disease (ACEGID), the genomic sequence of SARS-CoV-2 was performed using the QiAmp viral RNA mini kit (Paul, 2020). It is now clear SARS-CoV-2 can use angiotensin-converting enzyme 2 (ACE2), a receptor like SARS-CoV, to infect people (Zhou et al., 2020).

Like other CoVs, it is sensitive to ultraviolet (UV) radiation and heat, with high temperature reduces the frequency of any virus. In the meantime, the inactive SARS-CoV-2 temperature must be well elucidated. It looks like the virus can be inactivated at about $27^{\circ} \mathrm{C}$. On the contrary, it can withstand temperatures even below $0{ }^{\circ} \mathrm{C}$. Besides, lipid solvents can successfully inactivate this virus, including disinfectant of chlorine, ether (75\%), ethanol, peroxyacetic acid, and chloroform without chlorhexidine (Marco et al., 2020).

Reportedly, from the data provided by the WHO emergency dashboard on SARS-CoV-2 shown 7,625,883 confirmed cases, including 425,931 deaths in 216 Countries (as of 5:12 pm WAT, 12 June 2020). Considering case comparison reports, there are 225,491 confirmed cases in Africa; 2,152,756 in Europe; 3,718,697 in Americas; 1,519,477 in Asia; 8,766 in Oceania (ECDC, 2020). According to Nigeria Centre for Disease Control (NCDC) as of 12 June 2020, the SARS-CoV-2 outbreak had caused over 399 death and 9891 cases still active out of the 15,181 confirmed case with a population of 200 million people (NCDC, 2020).

The increase in cases reported by National Centre for Disease Control (NCDC) has been worrisome and the ways the testing are conducted needs to be improved or adjusted, thus, this review aims to focus on pathogenesis and new diagnostic techniques approach that can be adopted by the Nigeria health sector to tackle the low testing rates of SARS-CoV-2. This will enable the health government to answer the possible question "how can the spreading rate of COVID-19 be curtained through improved diagnostic methods?”.

\section{COMMON SYMPTOMS WITH COVID-19}

Symptoms of various cohort studies of SARS-CoV-2 patients vary in severity from having no symptoms at all (being asymptomatic) to having; Fever (most common symptom among mild to moderate cases) (Chang et al., 2020; Chen et al., 2020; Shen et al., 2020; Wang et al., 2020), Cough (second most common symptom observed in all studies) (Tian et al., 2020; Wu et al., 2020; Xu et al., 2020; Yang et al., 2020), Anosmia (loss of smell) (Tostmann et al., 2020). Dyspnea (shortness of breath) (Chen et al., 2020; Tian et al., 2020; Wang et al., 2020) etc. For the severest cases; acute respiratory distress syndrome, sepsis, severe pneumonia and septic shock, can all lead to death (ECDC, 2020).

If an individual is under investigation, it is recommended that practitioners put in place infection control and preventive measures immediately. Additionally, they recommend using

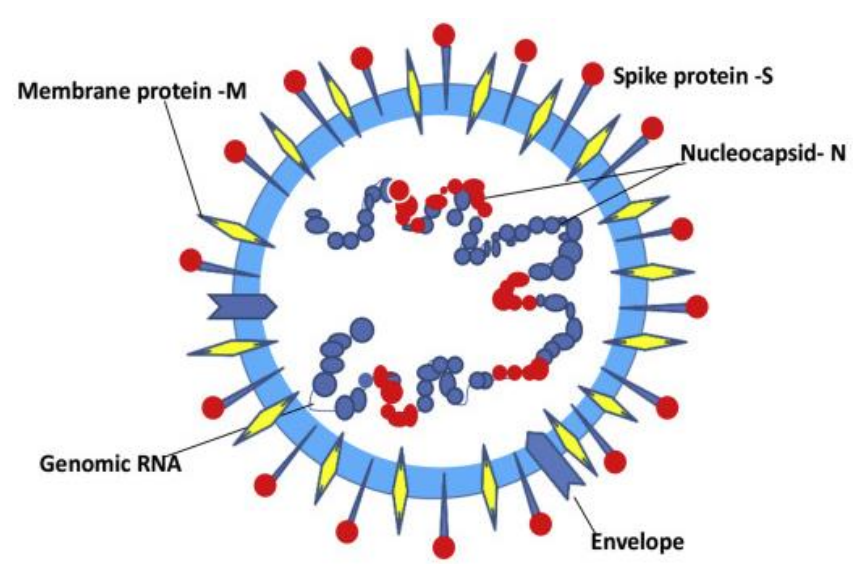

Figure 1. Diagrammatic Expression of SARS-CoV-2

Retrieved from: Li et al. (2020)

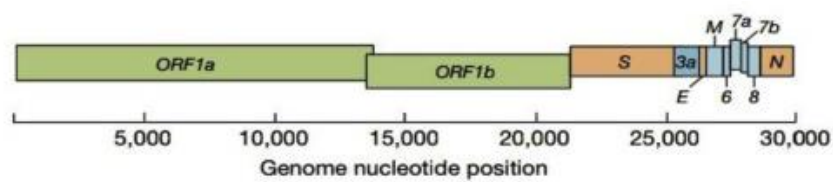

Figure 2. Genome-based of SARS-CoV-2 and the Genome Nucleotide Position

Retrieved from: Dinesh (2020)

ORF: Open Reading Frames, S: Structural Protein, N: Nucleocapsid. M: Membrane protein, E: Envelope protein

epidemiologic factors to aid in decision-making. There are epidemiologic factors that help decide who to test (Marco et al., 2020).

\section{GENOME PROPERTIES OF SARS-CoV-2}

With a viral genome length of about $29.9 \mathrm{~kb}$, the SARSCoV-2 composes of structural proteins like; S-spike protein (outer spiky glycoprotein), M-membrane protein (a type-III transmembrane glycoprotein), N-nucleocapsid protein (within the phospholipid bilayer) and non-structural proteins, encoded by the many genetic loci on the RNA of the virus (Figure 1). At its centre, lie a nucleocapsid composed of the genomic RNA and a capsid protein (Fehr and Perlman, 2015), which are all surrounded within a phospholipid bilayer, covered with two different types of spike proteins (Wu et al., 2020).

As shown in Figure 2, the genome of SARS-CoV-19 contains a variable number (6-11) of open reading frames (ORFs) including ORF1a/b, ORF3a/b, ORF6, ORF7a/b, ORF8, ORF9a/b and ORF10 (Song et al., 2019; Jin et al., 2020). The SARS-CoV-2 variant has a terminal 5'-end sequence of 265 nucleotides, and a 3 '-end sequence of 229 nucleotides, a common feature across all $\beta$-CoVs, with gene order $5^{\prime}$ replicase ORF1a/b- spike (S, 3822nt); envelope (E, 228nt); membrane (M, 669nt) and Nucleocapsid (N, 1260nt) -3' (Jin et al., 2020). 


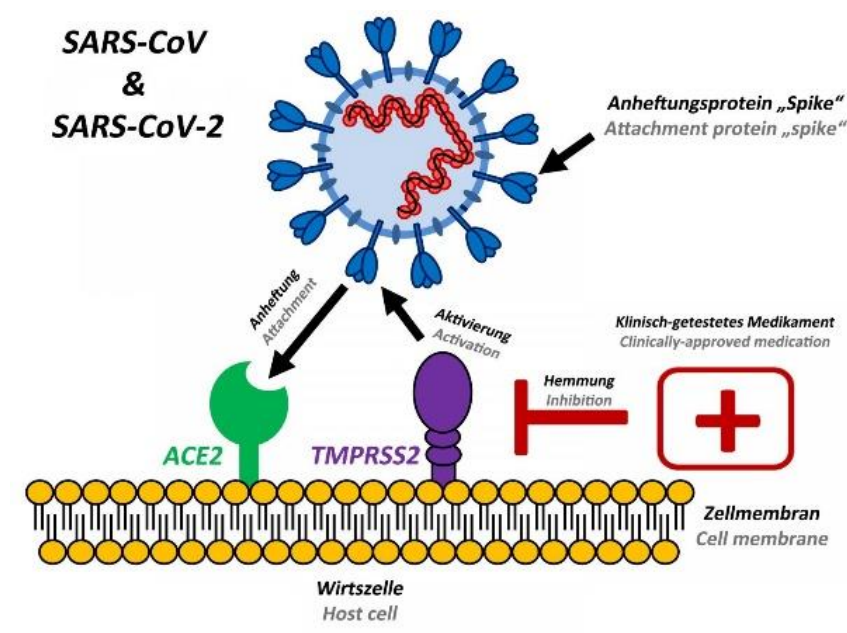

Figure 3. The Attachment Protein "Spike" of the novel Coronavirus (Sars-CoV-2)

Retrieved from: Hoffmann et al. (2020)

\section{REPLICATION AND MOLECULAR IMMUNE PATHOGENESIS OF SARS-CoV-2}

As earlier reported, SARS-CoV-2 contain specific genes in ORF1 downstream regions that encode proteins for viral replication, nucleocapsid and spikes formation (Jin et al., 2020). Just other $\mathrm{HCoV}$, glycoprotein spikes on the outer surface of SARS-CoV-2 cause attachment and entry of virus into host cells (Figure 1). Receptor-binding domain (RBD) is loosely attached to the virus, therefore, the virus can infect multiple hosts (Perlman and Netland, 2009; Raj et al., 2013). The coronavirus response pathway is dependent on cellular proteases including, human airway trypsin-like protease (HAT), cathepsin and transmembrane protease serine 2 (TMPRSS2) that differentiate spike protein and initiate other signaling changes (Bertram et al., 2011; Glowacka et al., 2011).

SARS-CoV-2 require angiotensin-converting enzyme 2 (ACE-2) as a key receptor activated by TMPRSS2 (Figure 3) used as a binding site for the spike (S) protein of the virus (Donoghue et al., 2000; Raj et al., 2013). ACE-2 is widely expressed in cells of the mucosa of the nose, trachea, bronchus, lungs, oesophagus, heart, kidney, stomach, ileum, and bladder, the virus uses it to infect target cells (Zou et al., 2020). The S-protein is present in the first pre-assemblage region consisting of two subunits: S1 and S2. The ACE2 receptor binding process begins with the $\mathrm{S} 1$ subunit establishing a destabilising pre-fusion state of the spike protein due to pre-fusion S1-S2-ACE2 trimmer, leading to the dissolution of the S1 subunit and the conversion of the S2 subunit into is a stable post-fusion state (Jin et al., 2020).

After the virus enters the host cell and becomes active, the genome is transcribed and translated at the cytoplasmic membrane, then incorporating integrated processes for continuous and irreversible RNA biosynthesis associated with viral replicate, a major protein encoded by the $20-\mathrm{kb}$ replicase gene, just as other $\beta$-CoV (Sola et al., 2015).

The host innate immune system detects viral infections by using pattern recognition receptors to recognise pathogen-

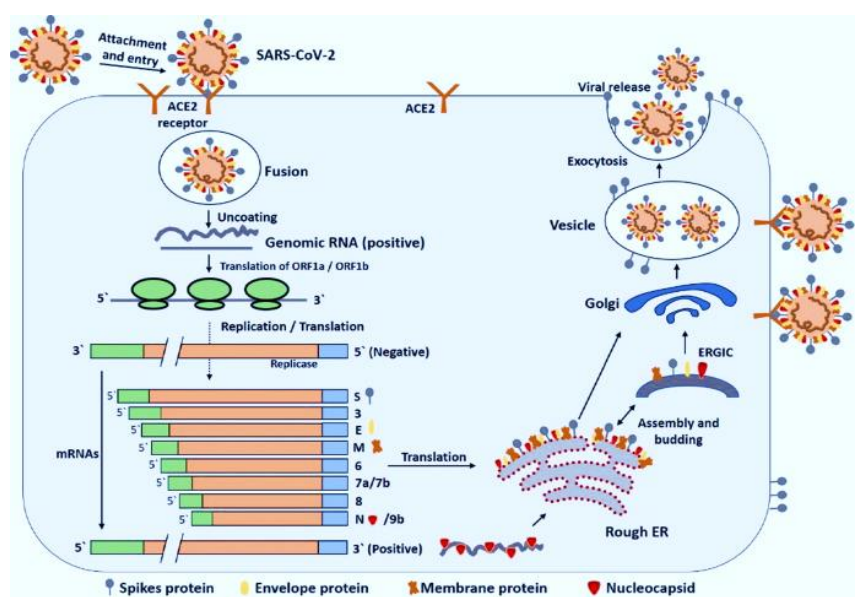

Figure 4. The Life Cycle of SARS-CoV-2 in Host Cells. It initiates its life cycle when the S-protein binds to the cellular receptor ACE-2. Conformational change in the $S$-protein following receptor binding facilitates viral envelope fusion with the cell membrane through the endosomal pathway. Then SARS$\mathrm{CoV}-2$ releases $R N A$ into the host cell. The genome RNA is translated into viral replicase poly proteins pp $1 a$ and $-1 a b$ and then broken down into minute products by viral proteinases. The polymerase generates a series of sub-genomic mRNAs through continuous transcription and is eventually translated into related viral proteins. Viral proteins and genomic RNA are then transported by vesicles assembled in the ER and the Golgi virions and released from the cell. ACE2: Angiotensin-Converting Enzyme 2; ERGIC: Endoplasmic Reticulum Golgi Intermediate Compartment.

Retrieved from: Muhammad et al. (2020)

associated molecular patterns. At present, the known PRRs mainly include C-type lectin-like receptors, toll-like receptor, NOD-like receptor, RIG-I-like receptor, and free-molecule receptors in the cytoplasm. The entire pathogenicity process of SARS-CoV-2, from attachment to replication is well illustrated in Figure 4.

\section{DIAGNOSIS METHODS}

Responding to the effects of the pandemic requires the application of diagnostic tests to detect the disease in people and quarantine them from transmitting the disease to others (Giordano et al., 2020). Currently, many tests to identify 2019 $\mathrm{nCoV}$ have been prepared or under development. Some tests can only detect a novel virus, and some other strain (e.g. SARSCoV) that are genetically similar (WHO, 2019). COVID-19 tracking and diagnostic testing are critical and critical to understanding epidemiology, informing case management, and to stifling transmission.

The basic types of COVID-19 test are:

i. Molecular testing using real-time reverse transcriptase polymerase chain reaction (RT-PCR)

ii. Antibody tests using blood

\section{Molecular Testing Using RT-PCR}

Various biological samples like nasopharyngeal swabs can be tested for SARS-CoV-2 presence. Respiratory removal of 


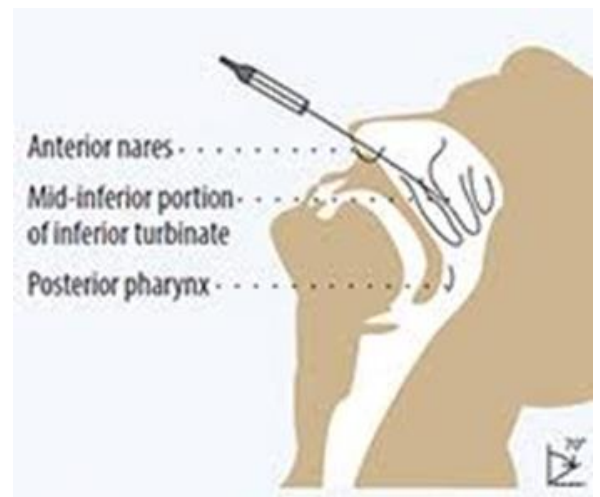

Figure 5. Sample Collection via Nasopharyngeal swabs Retrieved from: Loeffelholz and Tang (2020)

virus peaks at the end of the first week after infection, before symptoms develop. It may be intermittent, so a single negative swab result may be misleading and the tests have to be repeated (Huang et al., 2020; Zhang et al., 2020). The swab should be properly transported to the viral transport medium (Carver and Jones, 2020). Deep respiratory secretions including sputum and bronchoalveolar fluid are more virulent and in more severe cases the yield increases within 2-3 weeks (Loeffelholz and Tang, 2020; Zhang et al., 2020).

To collect the specimen, the swab is inserted into the nostril and slowly moves forward into the nasopharynx, the area of the pharynx that covers the roof of the mouth. The swab is rotated for a while to collect the secretions, then the swab is removed and placed in sterile viral transport media, which preserves the specimen for further analysis (Irving et al., 2012).

The Centers for Disease Control (CDC) has developed a test kit for testing patient samples for SARS-CoV-2. The test kit is called the CDC 2019-nCoV RT-PCR Diagnostic Panel. It is designed for use with certain software and some systems of PCR devices. This test is used with the upper and lower respiratory specimens collected from individuals who meet the CDC criteria for the SARS-CoV-2 test (CDC, 2020).

Test protocols require considerable equipment, factors and expertise and are often performed in central or regional laboratories, especially in poor settings of resources. Delay in transporting samples to the laboratory and returning the results to the Originator means the total test turnaround often exceeds 48 hours. Decentralisation of laboratories can help mitigate these delays, but close examination of the patient is urgently needed to provide more timely information for diagnosis and public health interventions (Dinesh, 2020; Sheridan, 2020).

\section{Serology (Antibody) Tests Using Blood}

Antibody tests are mainly used to determine if a person already has SARS-CoV-2. Specific immunoglobulin-M (IgM) and immunoglobulin-G (IgG) antibodies should begin detection after $4-5$ days, $70 \%$ of symptomatic patients were positive for 8-14 days, and $90 \%$ of all antibody tests were positive for days 11-24. IgG reactivity is expected to reach> 98\% after several weeks, although the duration of this antibody reaction is not yet known (Li et al., 2020; Zhao et al., 2020).
Antibodies can be detected with conventional enzymelinked immunosorbent assay (ELISA) tests or with lateral flow devices near the patient, like those used for pregnancy testing. These can give results in less than 20 minutes from a few drops of blood obtained through a finger prick. They usually combine tests for IgM and IgG, and the infection and sensitivity may not be positive until the second week after infection (Li et al., 2020; Okba et al., 2020). Poor specificity may also limit antibody detection tests, so people may be misdiagnosed as infected and have a false sense of security (Li et al., 2020).

\section{APPROACHING NEW DIAGNOSTIC TECHNIQUES FOR NIGERIA'S LOW SARS- CoV-2 TESTING RATES}

In a report released on March 30, 2020 by the directorgeneral of WHO, Dr Tedros Adhanom Ghebreyesus, he made a statement that the "coronavirus disease 2019 is here to stay and all countries, and organisations must put their house in order in managing it" (WHO, 2020).

As suggested by the WHO, the normal benchmark for testing new SARS-CoV-2 cases in countries with the Coronavirus disease is 10-30 tests per confirmed case (Roser et al., 2020). However, this is not the case in Nigeria where only 88,432 tests have been carried out with 14,554 cases in a population of 200 million people (NCDC, 2020). The more the testing capacity, the more the cases confirmed, and the better the strategies put in place to curb the effects of the coronavirus (Cheng et al., 2020).

With the current status of Nigeria, managing the disease effectively might be an arduous task for the government, healthcare workers, and organisations involved. The country is having issues with testing centres, low budget for managing prolonged health crises, and weakened healthcare system (Akpoveta et al., 2020; Medinilla et al., 2020).

Interestingly, researchers all over the world are working effectively in improving the methods used in testing SARSCoV-2 (Wang et al., 2020; Wang and Wong; 2020). The normal methods used in Nigeria which involved use of RT-PCR and Serology, require expertise and takes a long time before results are processed (Ibeh et al., 2020).

Coupling these new techniques below with the previous ones will help in significantly increasing the testing rates.

\section{Use of Saliva Samples as a Replacement to Nasopharyngeal Swabs (NPS)}

Currently, the standard method of sample collection for testing SARS-CoV-2 involves using nasopharyngeal swabs, in which a medical laboratory scientist will pass a nasopharyngeal tube into the nostril of the patient and pick droplets (Qian et al., 2020). This method of picking samples is not always comfortable for patients and it increases contact between the medical personnel and the patient (Beeching et al., 2020). Recently, two research groups from Royal Melbourne Hospital (Williams et al., 2020) and the Yale School of Medicine (Burki, 2020) confirmed that using Saliva as a replacement for NPSs is more sensitive and effective in detecting the presence SARS-CoV-2. The Yale group reported 


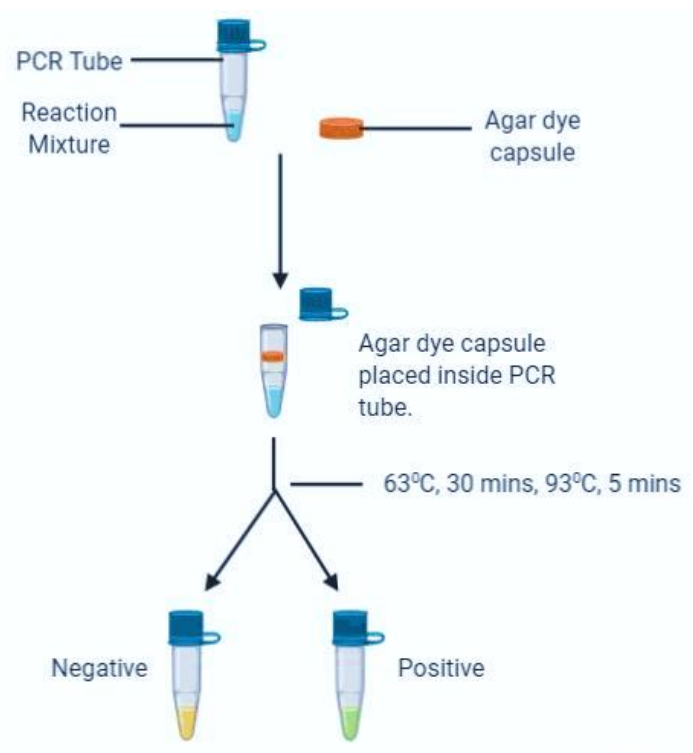

Figure 6. Loop-Mediated Isothermal Amplification Technique. The reaction mixture is prepared at placed in a PCR tube after which an agar dye capsule is added. The PCR tube is placed in a PCR machine and amplified at $63^{\circ} \mathrm{C}$ for 30 minutes and $95^{\circ} \mathrm{C}$ for 5 minutes. The colour changes in the reaction mixture indicate whether it is positive or negative. The result can easily be view with the normal human eyes. The agar melts at $95^{\circ} \mathrm{C}$ and becomes solid at room temperature.

Retrieved from: Karthik et al. (2014)

in their research that saliva collection does not involve use of any swab and it is pleasant for the patients. Medical personnel can easily take the samples from the patients without prolonged waiting and contact with the patients. They performed the research on 44 suspected patients by taking both their NPSs and saliva and sent them out for RT-PCR testing (Williams et al., 2020). Their results indicated that saliva has greater detection rates, and more sensitive all through the test than NPSs. In the Melbourne group, they also confirmed the sensitivity of saliva by carrying out a test on 622 people and confirmed 39 had COVID-19 with 33 of the patients detected using saliva samples.

Use of Loop-Mediated Isothermal Amplification (LAMP) in Testing COVID-19 Patients

A major challenge affecting the rates of COVID-19 testing globally is the requirement of a skilled professional in collecting, processing, and analysing test samples (Beeching et al., 2020). Besides, the level of logistics needed in sending samples to laboratory centres where the tests are carried out is important. The major test used for checking SARS-CoV-2 is the RT-PCR which is a sophisticated technique (Burki, 2020). All these problems are affecting many countries from meeting up with the WHO standard as regards the testing rate. For instance, in Nigeria, less than 100,000 tests have been carried out in a population of 200 million.

To provide solutions to these challenges, a research group from the Technion-Isreal Institute of Technology in Israel looked into the application of the LAMP technique in detecting the genetic material of the SARS-COV-2 virus (Ben-Assa et al., 2020). The LAMP technique was first discovered some years ago at Osaka University in Japan (Fujino et al., 2020). It is a nucleotide amplification technique that takes place at constant temperature and involves use of dye to affect colour change in detecting genetic material (Karthik et al., 2020).

The researchers at Isreal were able to change the steps involved in the techniques by including a reverse transcriptase step to detect the SARS-CoV-2 genetic material. As reported in their research work "SARS-CoV-2 spot virus detection directly from patients', they carried out clinical diagnosis directly on NPSs samples collected from patients without purifying or extracting the RNA of the coronavirus. Also, they performed the techniques on saliva samples and it was more effective" (Ben-Assa et al., 2020).

A research group performed this same technique at Well Cornell Medical School in NYC where they optimised the LAMP technique in detecting SARS-CoV-2 infection. In a trial carried out on 201 patients, they confirmed that 0.95 sensitivity and 0.99 specificity on a scale of 1 (Butler et al., 2020).

\section{RECOMMENDATION AND CONCLUSION}

Presently, the NCDC technical advisor points out that insufficient compatible equipment was a hindrance to rapidly scaling up COVID-19 testing in Nigeria.

Nigeria; expansion of her testing capabilities requires extra resources, for example, more examination groups, vehicles, and resources for sample collection and personal protective equipment. Groups need to move from house to house, working extended periods each day to look for individuals who may have gotten the infection. Tests are gathered from individuals who meet the standards for testing and the sample is then shipped to the appropriation point. The Nigerian ministry of health could embrace a new recipe which would offer her labs an alternative to waiting for or buying commercial tests.

Implementing use of saliva samples in testing for SARSCOV2 will be a significant step in the right direction for Nigeria. This will help in increasing the testing rates. Patients won't waste time waiting at the testing centres, and doctors can test more people in a shorter time. Besides, the money spent on NPSs swabs won't be needed anymore and it can be diverted into other areas to manage the pandemic. Furthermore, patients will be encouraged to come around for testing as many are not comfortable with use of swabs in taking their samples.

The major advantage of LAMP technique is, it is easy to use, it is fast and it can be performed without the need for an expert. Applying this technique in Nigeria will help in achieving high testing rates. Currently, Nigeria has limited testing centres and this has affected the turnover rates of testing results because the samples collected will have to be moved to the laboratory. The LAMP technique can be a solution to this problem because it can easily be operated and it does not require a high level of expertise and sophisticated equipment. Furthermore, the government is investing a huge amount of money in buying RT-PCR machines and constructing testing centres. With these techniques, they can direct the funds towards revitalising the economy and 
strengthening the health system. Besides, the techniques can be coupled with use of saliva samples which is more comfortable than NPSs at the point of collection.

Conclusively, looking at the merits of the new approaches of testing, it will be appreciable if the Nigeria ministry of health, NCDC and other health bodies involved, look, study and adopt this novel approach of testing, because it is timesaving, more efficient, does not require too deep knowledge of technical know-how and it saves cost.

\section{REFERENCES}

Ajari, E. E. (2020). Why Menstrual Health and Wellbeing Promotion should not be sidelined in Africa's response to COVID-19. European Journal of Environment and Public Health, 4(2), em0045. https://doi.org/10.29333/ejeph/8278

Akpoveta, O. A., Joy, O. and Joy, O. (2020). COVID-19 Pandemic: Nigeria's economic and business disruptions. International Scholar Journal of Arts and Social Science Research, 2(4), 14-31. https://doi.org/10.2705/isjassr.v2i4. 45

Beeching, N. J., Fletcher, T. E. and Beadsworth, M. B. J. (2020). COVID-19: testing times. British Medical Journal, 369, 1403. https://doi.org/10.1136/bmj.m1403

Ben-Assa, N., Naddaf, R., Gefen, T., Capucha, T., Hajjo, H., Mandelbaum, N. and Rotem, A. (2020). SARS-CoV-2 Onthe-Spot Virus Detection Directly from Patients. Available at: https://www.medrxiv.org/content/10.1101/2020.04.22. 20072389v2 (Accessed: 12 June 2020).

Bertram, S., Glowacka, I., Müller, M. A., Lavender, H., Gnirss, K. and Nehlmeier, I. (2011). Cleavage and activation of the severe acute respiratory syndrome coronavirus spike protein by human airway trypsin-like protease. Journal of Virology, 85(24), 13363-13372. https://doi.org/10.1128/ JVI.05300-11

Burki, T. K. (2020). Testing for COVID-19. Available at: https://europepmc.org/article/pmc/pmc7259912 (Accessed: 12 June 2020).

Butler, D. J., Mozsary, C., Meydan, C., Danko, D. C., Foox, J., Rosiene, J. and Ivanov, N. A. (2020). Host, viral, and environmental transcriptome profiles of the severe acute respiratory syndrome coronavirus 2 (SARS-CoV-2). Available at: https://www.biorxiv.org/content/10.1101/ 2020.04.20.048066v3 (Accessed: 11 June 2020).

Carver, C. and Jones, N. (2020). Comparative accuracy of oropharyngeal and nasopharyngeal swabs for diagnosis of COVID-19. Available at: https://www.cebm.net/COVID19/comparative-accuracy-of-oropharyngeal-andnasopharyngeal-swabs-for-diagnosis-of-covid-19/ (Accessed: 12 June 2020).

Centre for Disease Control, CDC. (2020). 2019-novel coronavirus (2019-nCoV) real-time RT-PCR diagnostic Panel. Available at: https:/www.fda.gov/media/134922/ download (Accessed:12 June 2020).
Chang, T. H., Wu, J. L. and Chang, L. Y. (2020). Clinical characteristics and diagnostic challenges of pediatric COVID-19: A systematic review and meta-analysis. Journal of the Formosan Medical Association, 119(5), 982-989. https://doi.org/10.1016/j.jfma.2020.04.007

Chen, G., Di, W., Wei, G. and Yong, C. (2020). Clinical and immunological features of severe and moderate coronavirus disease 2019. Journal of clinical investigation, 130(5), 2620-2629. https://doi.org/10.1172/jci137244

Cheng, M. P., Papenburg, J., Desjardins, M., Kanjilal, S., Quach, C., Libman, M., Dittrich, S. and Yansouni, C. P. (2020). Diagnostic Testing for Severe Acute Respiratory Syndrome-Related Coronavirus-2: A Narrative Review. Annals of Internal Medicine, 172(11), 726-734. https://doi.org/10.7326/M20-1301

Cui, J., Li, F. and Shi, Z. L. (2019). Origin and evolution of pathogenic coronaviruses. Nature Reviews Microbiology, 17(3), 181-192. https://doi.org/10.1038/s41579-018-01189

deWilde, A. H., Snijder, E. J., Kikkert, M. and vanHemert, M. J. (2018). Host factors in coronavirus replication. Available at: $\quad$ http://www.ncbi.nlm.nih.gov/pubmed/28643204 (Accessed: 10 June 2020).

Dinesh, K. (2020). An overview of coronaviruses including the SARS-2 coronavirus - Molecular biology, epidemiology and clinical implications. Current Medicine Research and Practice, 10(2), 54-64. https://doi.org/10.1016/j.cmrp.2020. 04.001

Donoghue, M., Hsieh, F., Baronas, E., Godbout, K., Gosselin, M. and Stagliano N. (2000). A novel angiotensin-converting enzyme related carboxypeptidase converts angiotensin I to angiotensin 1-9. Circulation Research, 87(5), 1-9. https://doi.org/10.1161/01.RES.87.5.e1

European Centre for Disease Prevention and Control, ECDC. (2020). Question and Answer on COVID-19. Available at: https://www.ecdc.europa.eu/en/covid-19/questionsanswers_(Accessed: 10 June 2020).

European Centre for Disease Prevention and Control, ECDC. (2020). COVID-19 situation update worldwide as of 13 June 2020. Available at: https://www.ecdc.europa.eu/en/geog raphical-distribution-2019-ncov-cases (Accessed: 12 June 2020).

Fehr, A. R. and Perlman, S. (2015). Coronaviruses: An overview of their replication and pathogenesis. Methods in Molecular Biology, 1282, 1-23. https://doi.org/10.1007/978-1-49392438-7_1

Fujino, M., Yoshida, N., Yamaguchi, S., Hosaka, N., Ota, Y., Notomi, T. and Nakayama, T. (2005). A simple method for the detection of measles virus genome by loop-mediated isothermal amplification (LAMP). Journal of Medical Virology, 76(3), 406-413. https://doi.org/10.1002/jmv. 20371

Geng, L., Yaohua, F., Yanni, L., Tiantian, H., Zonghui, L., Peiwen, Z., ... and Jianguo, W. (2020). Coronavirus infections and immune responses. Journal of Medical Virology, 92, 424-432. https://doi.org/10.1002/jmv.25685 
Giordano, G., Blanchini, F., Bruno, R., Colaneri, P., Di Filippo, A., Di Matteo, A. and Colaneri, M. (2020). Modelling the COVID-19 epidemic and implementation of populationwide interventions in Italy. Available at: https://www.nature.com/articles/s41591-020-0883-

7\#citeas (Accessed: 11 June 2020).

Glowacka, I., Bertram, S., Müller, M. A., Allen, P., Soilleux, E. and Pfefferle, S. (2011). Evidence that TMPRSS2 activates the severe acute respiratory syndrome coronavirus spike protein for membrane fusion and reduces viral control by the humoral immune response. Journal of Virology, 85(9), 4122-4134. https://doi.org/10.1128/JVI.02232-10

Guang, C., Di, W. and Wei, G. (2020). Clinical and immunological features of severe and moderate coronavirus disease 2019. Journal of Clinical Investigation, 130(5), 2620. https://doi.org/10.1172/JCI137244

Guo, Y., Cao, Q. and Hong, Z. (2020). The origin, transmission and clinical therapies on coronavirus disease 2019 (COVID19) outbreak: An update on the status. Military Medical Research, 7(11), 20-24. https://doi.org/10.1186/s40779020-00240-0

Hoffmann, M., Pöhlmann, S. and Diederich, S. (2020). SARSCoV-2 cell entry depends on ACE2 and TMPRSS2 and is blocked by a clinically-proven protease inhibitor. Cell, 181(2), 271-280. https://doi.org/10.1016/j.cell.2020.02.052

Huang, C., Wang, Y. and Li, X. (2020). Clinical features of patients infected with 2019 novel coronavirus in Wuhan, China. Lancet, 395, 497-506. https://doi.org/10.1016/ S0140-6736(20)30183-5

Ibeh, I. N., Enitan, S. S., Akele, R. Y. and Isitua, C. C. (2020). A Review of the COVID-19 pandemic and the role of medical laboratory scientists in containment. Journal of Medical Laboratory Science, 30(1), 68-89.

Irving, S. A., Vandermause, M. F., Shay, D. K. and Belongia, E. A. (2012). Comparison of nasal and nasopharyngeal swabs for influenza detection in adults. Clinical Medicine and Research, 10(4), 215-218. https://doi.org/10.3121/cmr. 2012.1084

Jin, Y., Yang, H., Wu, W., Chen, S., Zhang, W. and Duan, G. (2020). Virology, epidemiology, pathogenesis and control of COVID-19. Viruses, 12(372), 1-17. https://doi.org/ 10.3390/v12040372

Karthik, K., Rathore, R., Thomas, P., Arun, T. R., Viswas, K. N., Dhama, K. and Agarwal, R. K. (2014). New closed tube loopmediated isothermal amplification assay for the prevention of product cross-contamination. MethodsX, 1 , 137-143. https://doi.org/10.1016/j.mex.2014.08.009

Li, W., Moore, M. J., Vasllieva, N., Sui, J., Wong, S. K. and Berne, M. A. (2003). Angiotensin-converting enzyme-2 is a functional receptor for the SARS coronavirus. Nature, 426(6965), 450-454. https://doi.org/10.1038/nature02145

Li, Z., Yi, Y. and Luo, X. (2020). Development and clinical application of a rapid IgM-IgG combined antibody test for SARS-CoV-2 infection diagnosis. Available at: https://www.ncbi.nlm.nih.gov/pmc/articles/PMC7228300/ (Accessed: 12 June 2020).
Loeffelholz, M. J. and Tang, Y. W. (2020). Laboratory diagnosis of emerging human coronavirus infections: The state of the art. Emerging Microbes and Infections, 9, 747-756. https://doi.org/10.1080/22221751.2020.1745095

Lu, R., Zhao, X. and Li, J. (2020). Genomic characterisation and epidemiology of 2019 novel coronavirus: implications for virus origins and receptor binding. Lancet, 395, 565-574. https://doi.org/10.1016/S0140-6736(20)30251-8

Marco, C., Michael, R., Arturo, C. and Scott, C. (2020). Features, Evaluation and Treatment Coronavirus (COVID19). Available at: https://www.ncbi.nlm.nih.gov/ books/NBK554776/_(Accessed: 10 June 2020).

Medinilla, A., Byiers, B. and Apiko, P. (2020). African regional responses to COVID-19. Available at: https://ecdpm.org/ wp-content/uploads/African-regional-responses-COVID19-discussion-paper-272-ECDPM.pdf (Accessed: 11 June 2020).

Monchatre-Leroy, E., Boue, F., Boucher, J. M., Renault, C. and Moutou, F. (2017). Identification of alpha and beta coronavirus in wildlife species in France: bats, rodents, rabbits, and hedgehogs. Viruses, 9(12), 364. https://doi.org/10.3390/v9120364

Muhammad, A. S., Suliman, K., Abeer, K., Nadia, B. and Rabeea, S. (2020). COVID-19 infection: Origin, transmission, and characteristics of human coronaviruses. Journal of Advanced Research, 24, 91-98. https://doi.org/10.1016/j.jare.2020.03.005

Nigeria Centre for Disease Control, NCDC. (2020). COVID-19 in Nigeria. Available at: https://covid19.ncdc.gov.ng/ (Accessed: 12 June 2020).

Nigeria Centre for Disease Control, NCDC. (2020). Nigeria COVID-19 update; June 12, 2020. Available at: https://ncdc.gov.ng/news/237/update-on-covid-19-innigeria (Accessed: 12 June 2020).

Okba, N. M. A., Müller, M. A. and Li, W. (2020). SARS-CoV-2 specific antibody responses in COVID-19 patients. Available at: https://www.medrxiv.org/content/10.1101/ 2020.03.18.20038059v1 (Accessed: 12 June 2020).

Oluwafolajimi, A., Boluwatife, A., Ikponmwosa, G., Kenechukwu, F., Judith, O., Olayinka, A., Ifeoluwa, D. and Hilda, A. (2020). Current knowledge on the pathogenesis of and therapeutic options against SARS-CoV-2: An Extensive review of the available evidence. International Journal of Pathogen Research, 4(2), 16-36. https:/doi.org/ 10.9734/ijpr/2020/v4i230108

Paul. O. (2020). First African SARS-CoV-2 genome sequence from Nigerian COVID-19 case. Available at: https://virological.org/t/first-african-SARS-CoV-2genome-sequence-from-nigerian-COVID-19-case/421 (Accessed: 10 June 2020).

Perlman, S. and Netland, J. (2009). Coronaviruses post-SARS: Update on replication and pathogenesis. Nature Reviews Microbiology, 7(6), 439-450. https://doi.org/10.1038/ nrmicro2147 
Qian, Y., Zeng, T., Wang, H., Xu, M., Chen, J., Hu, N., Chen, D. and Liu, Y. (2020). Safety management of nasopharyngeal specimen collection from suspected cases of coronavirus disease 2019. International Journal of Nursing Sciences, 7(2), 153-156. https://doi.org/10.1016/j.ijnss.2020.03.012

Raj, V.S. Mou, H. Smits, S.L. Dekkers, D.H. Müller, M.A. and Dijkman, R. (2013). Dipeptidyl peptidase 4 is a functional receptor for the emerging human coronavirus. Nature, 495(7440), 251-254. https://doi.org/10.1038/nature12005

Roser, M., Ritchie, H., Ortiz-Ospina, E. and Hasell, J. (2020). Coronavirus Pandemic (COVID-19). Available at: https:// ourworldindata.org/coronavirus (Accessed: 11 June 2020).

Roujian, L., Xiang, Z., Juan, L., Peihua, N. and Honglong, W. (2019). Genomic characterisation and epidemiology of 2019 novel coronavirus: implications for virus origins and receptor binding. Lancet, 395(10224), 565-574. https://doi.org/10.1016/S0140-6736(20)30251-8

Sheridan, C. (2020). Fast, portable tests come online to curb coronavirus pandemic. Nature Biotechnology, 38(5), 515518. https://doi.org/10.1038/d41587-020-00010-2

Sola, I., Almazan, F., Zuniga, S. and Enjuanes, L. (2015). Continuous and discontinuous RNA synthesis in coronaviruses. Annual Review of Virology, 2, 265-288. https://doi.org/10.1146/annurev-virology-100114-055218

Song, Z., Xu, Y., Bao, L., Zhang, L., Yu, P. and Qu, Y. (2019). From SARS to MERS, thrusting coronaviruses into the spotlight. Viruses, 11(1), 59. https://doi.org/10.3390/ v11010059

Tian, S., Hu, N. and Lou, J. (2020). Characteristics of COVID19 infection in BeXuijing. Journal of Infection, 80, 401-406. https://doi.org/10.1016/j.jinf.2020.02.018

Tostmann, A., Bradley, J. and Bousema, T. (2020). Strong associations and moderate predictive value of early symptoms for SARS-CoV-2 test positivity among healthcare workers, the Netherlands, March 2020. European Communicable Disease Bulletin, 25(16), 2000508. https://doi.org/10.2807/15607917.ES.2020.25.16.2000508

Wang, C. J., Ng, C. Y. and Brook, R.H. (2020). Response to COVID-19 in Taiwan: Big data analytics, new technology, and proactive testing. Journal of the American Medical Association, 323(14), 1341-1342. https://doi.org/10.1001/ jama.2020.3151

Wang, J., Xu, Z., Wang, J., Feng, R., An, Y., Ao, W., Gao, Y., Wang, X. and Xie, Z. (2020). CT characteristics of patients infected with 2019 novel coronavirus: association with clinical type. Clinical Radiology, 75(6), 408-414. https://doi.org/10.1016/j.crad.2020.04.001

Wang, L. and Wong, A. (2020). COVID-Net: A Tailored Deep Convolutional Neural Network Design for Detection of COVID-19 Cases from Chest X-Ray Images. Available at: https://arxiv.org/abs/2003.09871 (Accessed: 12 June 2020).

Wei, G., Ting, G., Jinhua, L. and Wenlong, H. (2020). Novel coronavirus infection in children outside of Wuhan, China. Pediatric pulmonology, 55(6), 1424-1429. https://doi.org/10.1002/ppul.24762
Weiss, S. R. and Leibowitz, J. L. (2011). Coronavirus pathogenesis. Available at: http:/www.ncbi.nlm.nih.gov/ pubmed/22094080 (Accessed: 10 June 2020).

Williams, E., Bond, K., Zhang, B., Putland, M. and Williamson, D. A. (2020). Saliva as a non-invasive specimen for the detection of SARS-CoV-2. Available at: https://jcm.asm. org/content/early/2020/04/17/JCM.00776-20 (Accessed: 12 June 2020).

World Health Organization (WHO). (2020). Guidelines to help countries maintain essential health services during the COVID-19 pandemic; March 30, 2020. Available at: https://www.who.int/news-room/detail/30-03-2020-whoreleases-guidelines-to-help-countries-maintainessential-health-services-during-the-COVID-19pandemic (Accessed: 11 June 2020).

Wu, F., Zhao, S., Yu, B., Chen, Y. M., Wang, W. and Song, Z. G. (2020). A new coronavirus associated with human respiratory disease in China. Nature, 579(7798), 265-269. https://doi.org/10.1038/s41586-020-2008-3

Wu, J., Liu, J., Zhao, X., Liu, C., Wang, W. and Wang, D. (2020). Clinical Characteristics of Imported Cases of COVID-19 in Jiangsu Province: A Multicenter Descriptive Study. Clinical Infectious Diseases, ciaa199. https://doi.org/10.1093/cid/ ciaa199

Xu, Y. H., Dong, J. H. and An, W. M. (2020). Clinical and computed tomographic imaging features of novel coronavirus pneumonia caused by SARS-CoV-2. Journal of Infection, 80, 394-400. https://doi.org/10.1016/j.jinf.2020. 02.017

Yang, W., Cao, Q. and Qin, L. (2020). Clinical characteristics and imaging manifestations of the 2019 novel coronavirus disease (COVID-19): A multi-center study in Wenzhou city, Zhejiang, China. Journal of Infection, 80, 388-393. https://doi.org/10.1016/j.jinf.2020.02.016

Zhang, W., Du, R. H. and Li, B. (2020). Molecular and serological investigation of $2019-\mathrm{nCoV}$ infected patients: Implication of multiple shedding routes. Emerging Microbes and Infections, 9, 386-389. https://doi.org/10.1080/ 22221751.2020 .1729071

Zhao, J., Yuan, Q. and Wang, H. (2020). Antibody responses to SARS-CoV-2 in patients of novel coronavirus disease 2019. Clinical Infectious Diseases. ciaa344. https://doi.org/ 10.1093/cid/ciaa344

Zhou, P., Yang, X. L., Wang, X. G., Hu, B., Zhang, L. and Zhang, W. (2020). A pneumonia outbreak associated with a new coronavirus of probable bat origin. Nature, 579, 270-273. https://doi.org/10.1038/s41586-020-2012-7

Zou, X., Chen, K., Zou, J., Han, P., Hao, J. and Han, Z. (2020). Single-cell RNA-seq data analysis on the receptor ACE2 expression reveals the potential risk of different human organs vulnerable to 2019-nCoV infection. Available at: http://www.ncbi.nlm.nih.gov/pubmed/3217056024 (Accessed: 10 June 2020). 